\title{
Enhancing an Elementary Science Program: A Case History
}

One day at school my son just happened to volunteer that father is a "scientist," resulting in a request to lecture his science class and bringing me into direct contact with his sixth grade science text. After reading it $I$ understood why the teacher was having trouble with the materialapparently positive and negative charges weren't necessary for explaining such concepts as electrons, protons, and bonding. Fortunately, I had another resource, an out-of-print copy of Great Chemists edited by Eduard Farber (Interscience, New York, 1961). Its 320 years of vignettes, starting with Van Helmont in 1577 and ending with Sidgwick in 1922, provided an interesting one-hour lecture. It provided the opportunity to discuss safety in the laboratory, with Glauber's death in 1670 from years of exposure to mercury, arsenic, and antimony vapors as graphic illustration. And Boyle's discovery of formic acid from the distillation of ants raised a number of questions.

Have you had the opportunity to share your professional expertise through lectures for young people? If not, perhaps you have gone over your children's science or math homework, or helped with a science project. This type of professional in volvement in elementary education is necessary and beneficial, but too haphazard to challenge our problems in science education and awareness.

We are certainly aware that many children and adults in the United States have a rather limited knowledge of the complex interrelationships between science and technology and how they may impact our quality of life. The results of international competitive testing in science and math and the predominance of foreign students in graduate math, science, and engineering programs are not reassuring. On the whole, U.S. students are doing poorly compared with their peers in other countries.

Awareness of the problem is causing many to question present approaches and, in some cases, to advocate new directions. My experience indicates that although many ideas are available and professional people are willing to volunteer some time in an organized framework, the educational establishment is understandably preoccupied with the need to teach basics - reading, writing, and computation. The extras - equations and science, art, music - are often treated expediently. For instance, science demonstrations are not well thought out and are too complicated. Math contests where even the best stu- dents answer only 20 to $30 \%$ of the questions discourage those slightly less capable from appreciating and learning more complex math.

Although sympathetic to new endeavors, educators want no strings attached and no fiscal commitments beyond the nominal. In defense of educators, however, many school districts have funds adequate to cover only basic needs. Consider, for example, the extra costs involved with teaching the "exceptional" children. "Exceptional" children are those with learning disabilities, handicaps, or high intelligence. Unfortunately when dollars are tight, the latter are often forgotten, to our long-term detriment.

With all this pessimism, how do we approach the problem of educating our society to higher levels of scientific appreciation, and how do we encourage the most creative and capable students to enter scientific, mathematical, and engineering fields?

From my perspective as parent, volunteer professional, and elementary school PTA president, several new approaches seem viable:

1. The concept of discovery centers for materials science learning,

2. Elementary school math contests, and

3. County-organized science summer camps.

\section{Science Discovery Center}

To illustrate the needed planning and resources and how such activities could be implemented, I will focus on my experiences in trying to develop a discovery center in Chapel Hill, North Carolina. The discovery center was visualized as a set of materials-science-related labs that in their totality explain some part of the fabric of our modern world. Although the concept can encompass other areas, materials was considered especially appropriate because it offers a broad range of science and engineering experiences that would be fun and challenging for elementary school students. The discovery center, with a very small administrative overhead, would provide a focus and formal procedures to tap regional university, industry, and other community resources, including professional volunteers.

The cooperation of different scientific disciplines within such a center was intended to illustrate how science and technology either solve or avoid problems. Our idea was to carry out work in large trailers or "ScienceMobiles." Master teachers would bring hands-on experiments to each elementary school, to the benefit of both students and classroom teachers. A ScienceMobile would contain one of four modules: (1) Discovery of Minerals, Geology, and Mining; (2) Energy and Energy Requirements for Extraction, Refining, and Production of Materials; (3) Environmen$\mathrm{tal} /$ Ecological and Biological Effects of Materials Production, Use, and Disposal; or (4) Materials (Metals, Ceramics, Glasses,

Continued

\section{Federal Government's Role}

What is the role of the federal government in science education? Justifications of federal funding for science and technology are taken directly from the text of Public Law (PL) 94-282 which establishes that "federal funding for science and technology represents an investment in the future which is indispensable to sustained national progress and human betterment, and there should be a continuing national investment in science, engineering, and technology which is commensurate with national needs and opportunities and the prevalent economic situation." As policy, PL 94282 further establishes the need for recruitment, education, training, retraining, and beneficial use of adequate numbers of scientists, engineers, and technologists" to achieve stated goals.

To implement the enunciated policy in PL 94-282 the statute acknowledges that it is "an appropriate Federal function to support scientific and technological efforts which are expected to provide results beneficial to the public, but which the private sector may be unwilling or unable to support." It also states that "scientific and technological activities. . . supported ... by the Federal Government should be distinguished from those in which interests are shared with state and local governments and the private sector." This latter aspect often leads to confusion of responsibilities because of historical involvements by the different sectors and the scarcity of resources. The three sectors, taken together, are essential to developing the science and technology base needed for strong national security and maintaining the welfare of the people and economy. 
Polymers, Composites, Semiconductors, Wood) - Their Structure and Properties. The trailers were also intended to venture out to regional schools in an appropriate radius around the university center.

What about the costs of such programs? A science discovery center would be about \$130-\$150 per student, with evaluation costs of about $\$ 35$ per student for the first several years. Assuming $8 \%$ participation, math contest costs would be $\$ 63$ per student affected. A science camp can be estimated at $\$ 400$ per student. Some of these expenses could be borne by parents.

The following costs can be estimated for these programs on a national scale. A Learning Center Network targeting first through sixth graders $(810,000$ pupils $)$ would cost $\$ 105$ million per year after full implementation. Assuming that $0.2 \%$ of the U.S. population is in the third to sixth grade, with $8 \%$ having superior math abilities (43,000 students), total costs would be approximately $\$ 2.7$ million per year for the math contest. The additional funds would be about a $10 \%$ increase over the $\$ 3500$ average now spent annually per pupil.

What local dollar support is available for such programs? Aside from strong moral support, including in-kind financial and manpower commitments from biology, geology, and physics departments at the University of North Carolina and a favorable overhead rate from the university for our National Science Foundation costsharing proposal, we got few real dollars. After 12 months of negotiations, the community agreed to utilize the facilities if the National Science Foundation gave a fiveyear commitment of $\$ 906,000$.

From this experience, we learned the magnitude of effort required to coordinate the diverse groups involved in local education. A reservoir of good will and understanding among bench-level scientists and other professionals from university, industry, and the local community was identified. A skeleton nonprofit science education corporation in North Carolina was created.

We also learned that smaller initial objectives, such as the math contest and summer camp, may be more feasible. We learned that funding must be sufficient, first to test different approaches and then to implement the best over time. Local municipalities must be willing to share resources, and all participants must be prepared to work with school boards, school administrators, teachers, and parent groups. An obvious weakness of our efforts was a lack of costsharing. Some federally funded pilot programs do exist, but they require a minimum of $50 \%$ costsharing.

One benefit of the three new approaches proposed above would be to relieve an already harried educational establishment of some responsibility for specialized science and math education. Perhaps we should also seriously consider moving the responsibility for science education training to science departments. Prospective science teachers could take a necessary minimum of child psychology and pedagogics supplemented with a 9 or 18 -month stint as a teacher's aide. Teachers with an improved understanding will surely allow our schools to do a better job with science and math. Developing diverse funding mechanisms - beyond the traditional school tax - might also improve the climate for providing and creating excellence.

Our nation's most valuable resource is the creativity of its people. The maximum utilization of that creativity will occur only when all citizens appreciate its value through their own understanding of the contributions science and technology make to their lives.

ROBERT R. REEBER Materials Engineer Materials Science Division U.S. Army Research Office North Carolina

\section{AIP JOURNAL SUBSCRIPTION RATES for MRS Members}

Members of the Materials Research Society are entitled to special subscription rates on 10 journals published by the American Institute of Physics. To order contact Subscription Department, American Institute of Physics, 335 East 45 Street, New York, NY 10017; telephone (212) 661-9404.

Be sure to indicate that you are a member of MRS.

Journal of Applied Physics

Applied Physics Letters

The Journal of Chemical Physics

Journal of Mathematical Physics

The Physics of Fluids

Physics Today

Review of Scientific Instruments

Current Physics Index

Journal of Physical and Chemical

Reference Data

General Physics Advance Abstracts
Domestic Rates

\begin{tabular}{rr} 
Member & Nonmember \\
\cline { 3 - 3 }$\$ 80.00$ & $\$ 580.00$ \\
40.00 & 330.00 \\
100.00 & 935.00 \\
50.00 & 610.00 \\
45.00 & 535.00 \\
20.00 & 70.00 \\
30.00 & 345.00 \\
65.00 & 355.00 \\
55.00 & 240.00
\end{tabular}

12.00
Foreign Rates

(Including Canada \& Mexico)

Member Nonmember

$\$ 140.00$

75.00

$\$ 640.00$

365.00

175.00

1010.00

75.00

635.00

65.00

555.00

35.00

85.00

50.00

365.00

90.00

380.00

65.00

250.00 